\title{
The value of academics' research-related online writing
}

\author{
Niina Hynninen, University of Helsinki \\ Kathrin Kaufhold, Stockholm University
}

\begin{abstract}
Research productivity indicators tend to ignore online and social media writing of academics, nevertheless, many academics for instance tweet and blog. It thus seems that there is additional value for writing in these genres. This study sets out to explore what roles writing in these hybrid online genres plays in relation to academics' research activities. Drawing on in-depth research interviews with 29 academics with various L1s from three different disciplines, the study focuses on the participants' perceptions of tweeting and blogging, and how they value writing in these genres in relation to core research-writing genres in their fields. Besides some differences in the evaluations between the disciplines, in general the academics expressed a strong orientation towards evaluative regimes related to writing in their core genres, particularly institutional merit systems and peer review systems. At the same time, the hybrid genres seemed to gain value beyond these systems in providing opportunities for self-actualisation and communicating on one's own terms. The findings provide important insights into the ecology of genres academics make use of in the process of knowledge production.
\end{abstract}

Keywords: genre; tweeting; blogging; value; academic writing

\section{Introduction}

The role of online and social media in research-related writing has been looked at in terms of patterns of communication (e.g. Luzón, 2011, 2018; Myers, 2010), emerging genres (Kuteeva, 2016; Mauranen, 2013), changing patterns of professional academic work facilitated through the use of social media (Mewburn \& Thompson, 2013; Tusting et al., 2019), and more specifically in terms of the role of social media in collaborative writing (Hynninen, 2018; McGrath, 2016). While academics' use of social media, especially blogging and tweeting, has been discussed for over a decade now, we have neither seen its demise as considered by some (e.g. Myers' 2010 speculation on the death of blogs) nor an all-encompassing spread haling the democratization of knowledge (see discussion in Kuteeva, 2016). Formulated as questions, we could ask: Why doesn't everyone blog or tweet? Or alternatively, why do some continue to do that?

Corresponding author's email: niina.hynninen@helsinki.fi

ISSN: 1457-9863

Publisher: Centre for Applied Language Studies

University of Jyväskylä

(C) 2020: The authors

http:/ / apples.jyu.fi

http://dx.doi.org/10.17011/apples/urn.202005013003 
While the above studies consider forms, functions and patterns of online communication, we know less about the ways in which these means of communication are valuable and meaningful for scholars' research work. What we do know is that research article (RA) writing tends to be considered more prestigious compared to social media outputs, whereas social media carry a potential for wider dissemination beyond the relatively small communities of specialised researchers (Kuteeva, 2016; Weller, 2011). Reaching out to the general public has been increasingly promoted by higher education institutions, which potentially amplifies the usefulness of social media (Goodfellow \& Lea, 2014; Mauranen, 2013). Additional value of online writing derives from the fact that these "provisional texts [...] provide a space to try things out and learn to write" (Barton \& McCulloch, 2018, p. 13). Mauranen (2013) further observes that for instance blogging draws "on the very origins of science communication" ( $p$. 9). In general, the existing literature on academics' online writing indicates a strong link between the new, emergent, provisional genres and core research genres such as the RA. If we assume this intricate connection, in what way does it shape the meaningfulness or value of the new genres? In other words, in what ways do evaluative regimes (Lillis, 2013) that have historically evolved around types of writing in academic and other domains shape this online writing?

Research on academics' writing practices and the value academics attach to different types of writing illustrate the importance of national institutional frameworks and discipline-specific regulations. For instance, Tusting's (2018) study on scholars' perspectives on research-based writing illustrates how a national research evaluation framework (i.e. the Research Excellence Framework in the UK) can have a profound impact on their academic writing. Solin and Hynninen (2018), on the other hand, found in their case study situated at a Finnish university that discipline specific regulations and shared practices had a greater influence than institutional factors. Their research shows that evaluative and regulatory structures, be they national, institutional or disciplinary, clearly influence what academics do, especially in what genres they publish and which languages they choose for publication.

These studies also highlight that such evaluative structures are associated with competing environmental demands for academics. Nygaard (2017) suggests that juggling between such expectations and demands and scholars' multiple personal goals results in sites of negotiation (Flower, 1994; Ivanič, 1998) that require scholars to develop strategies and practices for coping with academic text production. In terms of genre, this means that scholars need to weigh not only between genres that count in research productivity indicators (e.g. whether to publish a research article or a book chapter) but also between those that do not count there at all (Nygaard, 2017). While online writing is linked to managerial demands on outreach activities (Barton \& McCulloch, 2018), it rarely counts in research productivity indicators, and thus the value for scholars must lie elsewhere. However, not much attention has been paid to what roles writing in different online genres play in relation to academics' research activities. For instance, writing a blog entry might function as an academic writing exercise (cf. Barton \& McCulloch, 2018) and might therefore gain value for RA writing.

This article seeks to shed light on the value academics attach to online writing in relation to their research activities. Based on in-depth interviews with 29 multilingual scholars conducted in the Language Regulation in Academia (LaRA) research project ${ }^{1}$, we examine in what ways online research-related genres are 
meaningful for academics in different disciplines. We focus on blogs and tweets because the participants discussed writing in these "hybrid genres" (Barton \& McCulloch, 2018, p. 13) as partly overlapping and complementary in relation to research activities. We examine how academics evaluate these genres and position themselves in relation to specific evaluative regimes that impact what writers must do in order for their writing to be accepted by their target audiences (Lillis, 2013). Specifically, we ask:

a) How do academics evaluate writing in different hybrid online genres?

b) How do academics value these genres in relation to core research-writing genres in their field?

We look at the meaningfulness of online writing for academics beyond institutional pressures (cf. Barton \& McCulloch, 2018), as well as the roles the selected genres play for their writing practices and knowledge production. The way scholars evaluate these hybrid genres indicates how these genres support or otherwise relate to the academics' core research writing activities.

Our findings contribute to research on the ecology of academics' professional writing practices by shedding light on how academics value different hybrid online genres that complement their research-related communication. We identify similarities and differences in the perceptions of academics in different disciplines and at different career stages. We demonstrate that in their evaluations, academics orient to various "real or perceived 'centres'" of "evaluative authority" (Blommaert, 2010, p. 39), and in doing this, position themselves in relation to specific evaluative regimes. We suggest that the genres gain their meaning, but not their form, from research writing (cf. Kuteeva \& Mauranen, 2018). And we reveal how writing in these genres is valued in terms of reaching additional groups of stakeholders, such as scholars in other fields or potential research participants. These insights indicate directions these genres seem to be taking in regard to research-related work.

\section{Theoretical framework: evaluative regimes and sets of genres}

Research-based writing is now generally understood as social endeavour (Bazerman, 1994; Miller, 1984; Swales, 2004), as meaningfully acting in the world (Lillis, 2013). As such, academic writing is embedded in academics' professional practices (Bhatia, 2004) and in social power relations that regulate writing (Solin \& Hynninen, 2018; Street, 2003). Lillis (2013) uses the term "evaluative regimes" to highlight the role of institutions, such as academia, in shaping what is perceived to be appropriate writing. In general, such regimes relate linguistic behaviour to power structures in that they encompass "mechanisms of restriction, authorization, or valorization" (Etrillard, 2019, p. 2) that delimitate what counts as appropriate or inappropriate behaviour in specific contexts. Evaluative regimes can thus be understood as value systems that shape genres associated with specific domains (and institutions) in that they enable and constrain what writers must do in order for their writing to be accepted and valued by their target audiences. However, evaluations of what counts as acceptable writing in one domain might orient to different centres of evaluative authority (Blommaert, 2010), for instance, managerial and discipline-specific principles in the case of 
RA writing (Tusting, 2018). Hybrid genres, such as blogs that are situated between popularisation and scientific writing (Mauranen, 2013), might require the writers to orient to more diversified centres of evaluative authority.

We adopt the view of "genre as action" (Lillis, 2013, p. 70) introduced by Miller (1984) and defined as recurrent patterns of language use "organized around situated action" (p. 155). We identify genres based on how the study participants construct and evaluate their online writing in relation to their research activity as opposed to other areas of their work, such as administration or teaching. Genre is thus not defined based on its textual form but "on the action it is used to accomplish" (Miller, 1984, p. 151) from the writers' perspectives.

Genres relate to each other in different ways within and across domains. Devitt (2004), for instance, talks about sets of genres and how a group usually operates through a set of genres consisting of texts with varying formal and material features to achieve their purposes. She further suggests that "[a]s the needs of the group change, the genre set changes to reflect those needs" (Devitt, 2004, p. 54). Against this background, the hybrid genres discussed in this paper broaden the genre set of academics as a response to the changing needs of this group. The question then is, how do these new genres relate to each other and other genres academics write in? Notions such as genre chains (Fairclough, 2003) may be useful in this regard. The notion of genre chains shifts attention towards the ways in which certain texts routinely cluster together, highlighting "systematic transformations from genre to genre" (Fairclough, 2003, p. 216). However, as Lillis (2013, p. 123) points out, the clustering does not take place because of the formal or textual features of the texts "but because of the ways these texts are produced, received and [...] acted upon". With this in mind, we can conceptualise how the hybrid genres in our study are valued for accomplishing a specific action in a chain of genres, for instance as kinds of promotional texts written as a response to the increasing need of academics to promote their work (cf. Fairclough, 2003). Investigating the overlaps and contradictions in these evaluations provides insights into the ways in which hybrid genres serve meaningful functions in academics' knowledge production.

\section{Methodology}

Due to our interest in expressed perceptions and evaluations of writing and textual products, this study is an interview-based study (Kvale \& Brinkman, 2009). The data were collected as part of the Language Regulation in Academia (LaRA) research project (see endnote 1) from two multidisciplinary universities in Finland. They comprise in-depth interviews with 29 academics with 11 different L1s from history (9), geology (7) and computer science (CS) / human computer interaction (HCI) (13) at different stages in their career, including doctoral students, postdoctoral researchers, senior lecturers/researchers and professors. The academics discussed their writing processes of online and offline genres relating to their research activity. The interviews, conducted by the first author, were in English or in Finnish and typically lasted 1-1.5 hours. Informed consent was obtained from all participants. The recordings were transcribed verbatim (see Appendix A for transcription conventions), and Finnish-language extracts used in this paper have been translated into English by the first author.

The data analysis was conducted in two stages. First, we selected six interviews, two from each discipline, to identify relevant genres, categorise what 
about these genres was evaluated (stance objects, see below), and trace the evaluation of these stance objects throughout the interview interaction. The criteria for the selection were that the interviewee reflected on online hybrid genres and related these genres to his or her research activity, and that the sample included one junior academic and one more experienced academic per discipline. Second, we extended our analysis of the identified genres to the entire data set by searching for instances where these genres were discussed. The first stage facilitated analysis of how the academics' evaluations of the hybrid online genres progressed and how they shifted in the course of the interview interaction, whereas the second stage enabled us to add a cross-sectional perspective.

We started the analysis in stage one by identifying the hybrid genres discussed in the pre-selected six interviews. To analyse the participants' evaluations in the talk about genres and in the comparison between genres, we applied the sociolinguistic concept of stance taking (Jaffe, 2009). In stance taking "the stancetaker (1) evaluates an object, (2) positions a subject (usually the self), and (3) aligns with other subjects" (Du Bois, 2007, p. 165). Stance taking thus highlights that evaluations are always connected to specific stance objects and that an evaluation is a social act of relating to the interlocutor or other subjects. Thus, to understand how academics value writing in different genres, we identified in detail what about writing these genres the academics commented on. This resulted in the following list of stance objects:

- Genre: using or writing in a particular genre, especially comparing different genres to one another

- Textual product written in a particular genre

- Quality and form of the textual product: scholars' expectations related to the scholarliness/aesthetics and the linguistic form (e.g. acceptable, good, functional)

- Choice of language: scholars' expectations of writing in a particular language

- Writing process: the practice and purpose of writing in the genre

- Writer's own contribution: self-actualisation and career merit

To identify evaluations in the interviews, we used Biber and Finegan's (1989) model of stance markers. In contrast to the broader sociolinguistic concept of stance taking, which describes a social action, stance markers are lexical items that denote certainty, doubt or affect, as well as hedges (e.g. "kind of"), emphatics (e.g. "just", "really") and modal verbs of possibility, necessity, and prediction (e.g. "could", "should", "would") (Thompson \& Hunston, 1999, p. 19). That is, stance markers are a part of the manifestation of stance taking.

To pay attention to the social positioning in stance taking, we traced how each of the six participants evaluated the stance objects throughout the interview. Following the stance taking provided clarifications as well as contradictions. For instance, a writer might evaluate her blog writing in terms of textual quality as playful highlighting the creative aspect and positioning herself as a creative writer, while she might later comment that this playfulness is not appropriate for RA writing thus positioning herself as a serious researcher. Such contrasts point to competing centres of evaluative authority affecting the genres.

In stage two, we conducted a cross-sectional analysis (Mason, 2002) with the aim of comparing the stance taking across the interviews. We searched for talk around the online hybrid genres we identified in stage one across the entire data 
set and looked for other examples of the stance objects found in the first stage. The evaluations expressed in these excerpts were compared to our findings from stage one to broaden our understanding of how the participants valued hybrid online genres.

Key for this study is the participants' evaluation in their stance taking and their positioning towards different centres of evaluative authority, not how exactly this is manifested in the textual products (i.e. blogs or tweets). Therefore, unlike in many other studies that discuss genres, we do not include an analysis of written texts of our participants as manifestations of genres. Our main interest is in how the participants make sense of their writing when talking about their writing, as this is a fruitful way to gain insights into what makes writing in the different genres meaningful for academics.

\section{Results}

This section presents the study participants' perspectives on their use of online genres in relation to their research work. We focus on blogs and tweets which have been most extensively discussed in the interviews. The analysis is presented around focal excerpts which are extended by reference to shorter excerpts from the entire data set.

\subsection{Blogs}

The focal excerpt around blogging (see Appendix B) is from an interview with a multilingual historian who at the time of interviewing worked as a postdoctoral research fellow at a multidisciplinary university in Finland (His07). Before coming to Finland, His07 had completed her $\mathrm{PhD}$ in another European country and done archive research in several others. She placed her research under general history, but with elements from different strands of historical study. Throughout the interview she alternates between evaluating her blogging as playful self-actualisation or as additional means for research outreach. She thereby orients to different centres of evaluative authority.

In terms of the stance object genre, His07 compares her blog writing with her core research genres (research articles, book chapters and monographs), which she characterises as "actual scholarly writing", and from science popularisation (see Kuteeva, 2016; Mauranen, 2013):

(1)

I mean it's not as well thought, as actual scholarly writing in fact I don't really go into anything, in great detail. But it is very, it's very specific. So I don't think you could say like it's (popular), like you wouldn't stumble upon it and think oh everything in this blog is interesting, unless you're me.

Yet later-on she also recognises overlaps between her blogging and her scholarly work:

(2)

I mean, there's definitely a sort of overlap in terms of like, the blog (about [topic]) at the time when I was writing a number of articles about [topic] [...] what I write in (those) scholarly journals is very much about my research and nothing but that and (then) sort of my personal notions of, don't yeah, come in to that. 
In this genre comparison, she characterises her blogging as dealing with her research topics. At the same time, she evaluates her RA writing as her core activity when characterising it as "actual" and with emphatic expressions such as "very much" and "nothing but". She links this hierarchy also to her career progression and the merit system based on publication: "if I really analyse something through, it's going to be published properly and it'll be a line in my $\mathrm{CV}$ at some point".

A substantial part of her evaluation focuses on the stance object of quality and form of the text. In contrast to popularised writing, the blog is "very specific" and relates to her research topics. However, in contrast to scholarly writing, she describes the blog writing as "not nearly sufficiently nuanced to actually write down as a scholarly paper" and "not as well thought". She further evaluates the quality of the textual product as light-hearted, using expressions such as "vaguely amusing", "non-boring", "slightly witty", "little snippets". This lightheartedness is clearly a feature of blog writing for her, which she explicitly excludes from her scholarly writing.

She takes a stance towards the writer's own contribution and evaluates her blog in terms of self-actualisation as "playground", where she can write about what interests her:

(3)

Like at the moment it's really just my personal playground and I sort of think like, (oh) this is amusing I'll write something about it. Sometimes people like it and sometimes they don't [...] it doesn't have a massive readership, of of any kind [...] so it doesn't really matter.

The reference to "play" underlines the light-hearted nature of the blog further. In the course of her reflection, she links this quality to the stance objects of writing process and language choice and describes her blog writing as an exercise in "playing with words" in English as an additional language (see historians' ideals of aesthetic writing, Hynninen \& Kuteeva, 2017). Interestingly, in this reflection on her language choice she shifts her stance from focussing on self-actualisation to her research activity and potentially reaching scholars in her field in English:

(4)

I think both sort of the exercise of of, trying to write in a non-boring way in a language that is not my own. [...] And also because I do sort of share some research interests with colleagues who obviously don't speak [L1]. And increasingly I sort of meet people and know people who don't speak the language and who might be interested in, in these little snippets. So it makes sense I think, to do it.

She concludes this part with the notable remark "so it makes sense... to do it", that is, for this multilingual writer, the blog is a language exercise that makes sense if her colleagues from different parts of the world read it.

We can thus see how His07 develops her stance towards her blog in relation to the different stance objects and thus provides insights into what makes blogging meaningful for her. She foregrounds self-actualisation, but importantly, the blog is also validated by professionals and other scholars reading it. In fact, later-on in the interview, she recounts how she has been contacted by professionals who might not have read her published work had it not been for the blog. In effect, the blog is an indirect means of research dissemination (see 
Barton \& McCulloch, 2018) and, more importantly, networking. Her evaluation thus relates to different centres of evaluative authority, associated with play on the one side and research potential on the other. It is precisely this combination of play and research potential that seems to make the blog meaningful for her.

In the wider data set across the three disciplines (and in line with the hybrid nature of online genres), academics evaluated blogs based on different actions they help to accomplish with different audiences in mind (see e.g. Mauranen, 2013). Blogs were framed as comments on research (as in the focal excerpt); as targeted means of research dissemination (e.g. for project teams or for those supporting museums); or as a source of up-to-date information or debates especially in the form of science blogs (Mauranen, 2013). Younger academics also referred to blogs that provide tips on academic writing (CS01, CS10).

Irrespective of this variety, interviewees across the three disciplines and across career stages discussed blogs in terms of the stance object of genre and agreed that the core research genres are more prestigious: "blogs don't merit you as much as RAs do" (His05, postdoc). Geo07 (doctoral student) while commenting on science blogs explained that "a blog just is for the opinion, instead of the fact", and His04 (research fellow) and Geo02 (postdoc) cautioned that blogs do not always contribute to research. Research project blogs are a clear exception here and some of the scholars had cited research made available on such blogs that had not yet been published through traditional peer-reviewed channels (His05). In general, less established research areas seemed to be more open to this practice (e.g. His07 compared sound studies with medical history). Several scholars mentioned the increasing importance of blogs in their fields, especially among scholars in the US (Geo02) or Britain (His05), while not necessarily seeing their value for their own research (e.g. Geo02).

In terms of the stance object of quality and form of the textual product, especially historians concur with His07's evaluation of blogs being fun (His04, His09), freer and requiring less thorough consideration on how to formulate arguments (His01). Interestingly, His05 suggests that this quality requires a certain writing skill and wit underlining that the freedom experienced in writing in comparison to RA writing does not mean anything goes but indicates another centre of evaluative authority. In addition, while His07 suggested paying less attention to grammatical correctness, His01 and His05 suggested the need to modify language and check for grammatical mistakes. Others viewed this entertaining side more negatively and characterised social media texts as "chatty" and "gossipy" (Geo01). So while the light-heartedness seems to be a core characteristic, it is evaluated both in positive and negative terms. These diverging views highlight the hybridity and evolving nature of blogs in research-related contexts.

Regarding the stance object of writing process or how others' blogs facilitate one's own research, blogs were described as providing a space for "open discussions" (CS07) or "high level discussions" (His09) around current topics. In line with His07, others commented on blogs as providing a potential means for networking (His05, Geo01) and finding links to relevant literature (His04, His05, CS01, CS10). For instance, His02 suggested that blogs provide a faster way to learn about new book publications than journals can. For others the need to invest time in following blogs outweighed the advantages (His03).

As in His07's case, the language choice depended mainly on the target audience. For instance, a history professor (His09) suggested that the language 
choice for his research project blog was Finnish because the research topic was specific to the Finnish context. A professor in computer science (CS03) presented English as the natural choice because the research project targeted international companies, whose language is English.

Concerning the stance object of writer's own contribution, we identified additional evaluations pointing to further centres of evaluative authority. First, researchers mentioned the benefits of sharing (His09) their research "without going through the reviewing process" (His04), which clearly recognises the authority of peer review practices in research publishing but at the same time questions this authority. Second, those who related to writing blogs for outreach to the general public suggested that they were able to "serve the public" and provide "more accurate information" than through other popular channels available (His01, also Geo01). Finally, for a team of computer scientists, their project blog facilitated outreach to businesses and potential recruitment of research partners (CS03).

The connection to attracting research participants as well as the qualification of the accuracy of the information clearly ties in with core research tasks of the scholars. In the evaluations of all stance objects, the participants across the wider data set position themselves predominantly as researchers and orient to centres of evaluative authority connected to their institution or discipline. Blog writing gains value in that it relates back to research as core activity of the scholars.

\subsection{Tweets}

Tweets were another online writing genre discussed extensively by the participants. In what follows, we explore talk around this genre by starting out with a focal excerpt (see Appendix C) from CS07, who at the time of the interview worked as a research fellow in HCI at a multidisciplinary university in Finland. Before starting as a research fellow in this university, she had completed her PhD in another European country and worked at other universities in Finland and elsewhere in Europe. CS07's background was in computing science, but since she worked in the interdisciplinary field of HCI, her research projects were similarly interdisciplinary and included a lot of collaboration with colleagues in Finland and beyond.

In the interview, as a response to a question about the role of social media in her work, CS07 started talking about Twitter as her "work thing". In her evaluations of tweeting, she orients to centres of evaluative authority connected to research benefits and to building a disciplinary community. She dedicates a major part of her evaluation to commenting on the stance objects of genre and writing process, specifically how tweeting enables communication and networking among scholars:

(5)

I've increased my use more, and started following, more people and taking part in, discussions. [...] and then I, I've ended up getting to, conversations with people who I would never meet otherwise [...] and then there's ended up being projects that have started because of, these things [...] it makes it feel more like you're part of a community

In relation to the stance object of genre, CS07 engages less in comparison of the genres and instead underlines the compatibility of the genres. In terms of the 
stance object of writing process, CS07 describes the practice of tweeting as a way to "tak[e] part in... discussions" and engage in "conversations" with the disciplinary community. The value for research-related tweeting for her comes precisely from being this dialogic medium for communication that enables networking.

More specifically, again orienting to the stance object of writing process, CS07 mentions herself and others tweeting about interesting papers and thus providing access to key literature for the writing of core research genres:

(6)

Twitter is my sort of, online source and sometimes, it leads me to things I wouldn't read otherwise, you know, because I wouldn't find them probably if I was searching for

This communicative value is also reflected in CS07's evaluation of tweeting in terms of the stance object of writer's own contribution. She describes the genre of tweets as meaningful for research group visibility ("we should really be sharing what we're doing"), and indirectly career merit that the visibility may help achieve. CS07 thus values tweets mainly in terms of them being a useful, if not crucial, communication channel in the field.

In terms of the stance object of textual product, and particularly the linguistic form, CS07 commented:

\section{(7)}

you wouldn't, use such formal language as you would use in a publication, in a, in a tweet. It's definitely much more, casual and usually people are actually just tweeting a link to a paper or, a link to something else, there's.. in the tweets themselves there's actually very little information or, or, content there. Erm, (but yeah that) that's also kind of nice because then these big scary researchers or professors that you've seen, they seem more human when you can, read their tweets and, also see if they've made spelling mistakes or, that kind of things@@. Yeah.

CS07 describes the language of tweets as less formal and less polished than writing for research publication, to the extent that it makes "these big scary researchers or professors... seem more human". These characteristics relate to the immediacy of tweeting, which sets it apart from the more complex research writing processes and products. In all, in CS07's depiction, tweets receive their value as a medium that brings academics and their work closer together. That is, tweets seem to be valued not as a research writing genre per se, but a channel through which to find texts written in those genres.

Overall in our data, irrespective of career status, scholars varied in terms of how much, if at all, they tweeted and how they viewed tweeting. For instance, as active tweeter, a postdoc in history (His05) described Twitter as "absolutely brilliant", as she had received invitations abroad and built her network through it, whereas a non-user, another postdoc in history (His07), said that "Twitter is sort of coming up, but I'm not on Twitter and I, I'm not fantastically interested if I'm really honest @@". Disciplinary-wise, computer/HCI scientists were among the most active ones, with 9 out of the 13 study participants using Twitter for work (see Hynninen, 2018). In fact, CS06 described social media as important for "competing for the attention we can get" when references for research publications are chosen "from within a two-year time span". This suggests a degree of shared value for tweeting in CS/HCI. CS03 further suggested that his 
research group use social media in order to better understand them as a phenomenon used in the business world. In contrast, none of the geologists reported using Twitter, with Geo02 describing geology as an "old-fashioned field in terms of social media platforms". Even if there was individual variation, shared disciplinary views thus seem to count in the academics' choice to tweet or not.

In terms of the stance object of genre, similarly to CS07, those active on Twitter (e.g. CS06, His05) emphasised its networking potential and the sharing of research results, also to stakeholders (CS03, CS06). Many participants reported that they get or share links to research literature, but also blogs through Twitter. For instance, CS03's research group had plans to discuss their research and provide open access versions of their research publications in a project blog and advertise all this by tweeting. Twitter was thus seen as a means to gain and increase visibility for one's own or one's research group's research (cf. Tusting et al., 2019), as well as for sharing and finding that of others (see Hynninen, 2018). In this sense, part of the value of tweeting relates to the stance objects of writer's own contribution and writing process, here how following tweets facilitates one's own research.

In terms of the stance object of textual product, computer/HCI scientists described tweets as providing "diversion" (CS08) and a platform for "interesting discussions" and "jokes" (CS01) around the time of shared conference paper submission deadlines. Tweets thus seem to be associated with a certain element of light-heartedness. The choice of language was reported to relate to the target audience, with English being the main medium for research-related tweeting (CS03, CS06).

In all, the findings illustrate that in their evaluations, the participants oriented to different evaluative authorities in that they oriented to tweeting from the perspective of its perceived research benefits but also as a tool for disciplinary community building and wider networking.

\section{Discussion}

How do academics evaluate writing in the hybrid online genres?

Academics evaluated the hybrid online genres discussed in this article by stance-taking towards different stance objects related to the genres. Central to the evaluation of blogs was the potential for outreach to stakeholders within and outside academia on the one side and trying out ideas on the other side. In contrast to research in the UK and US (Barton \& McCulloch, 2018; Weller, 2011), the interviewees situated in Finland did not mention managerial pressures to use social media but framed the outreach to the general public in terms of enlightenment and civic duty (Hynninen \& Kuteeva, 2020). Testing ideas and networking with other academics within and outside the field as well as potential research participants was evaluated positively if the interviewees connected it to their career merits in terms of the furtherance of their core research work. In this sense, they oriented to institutional promotion policies as a centre of evaluative authority and positioned themselves in relation to the evaluative regime of RA writing which uses publications as a condition for career advancement (e.g. Tusting, 2018). 
In terms of the stance object of textual product, first, the choice of language for a blog was described as variable and depended on the target audience. Second, the light-heartedness of the texts, whether positively or negatively evaluated, was mentioned as a quality that distinguished blogs from core research genres. For those engaged in blogging, the text had to fulfil certain requirements including maintaining a scientific level, a level of language correctness and some wittiness and thus clearly required skill (cf. Curry \& Lillis, 2019). Those who were more sceptical towards blogs considered the content as too opinionated and the light-heartedness as chatty. These different evaluations partly relate to the different forms of blogs as discussion forum within the field, research reflection, or public outreach channel. The writers continued to position themselves as academics indexing evaluative regimes of RA writing while at the same time moving away from forms of writing in their core genres. Some connected blogging to their writing process of research outputs and used it as a testing ground (cf. Barton \& McCulloch, 2018). In their evaluation, the interviewees considered their potential audience when evaluating their discursive choices but did not identify any institution (in the widest sense) as evaluative authority. Instead, they clearly distinguish their work from science popularization.

Our participants valued tweets because these afforded networking and sharing sources. Similarly to the use of blogs, academics mentioned how tweets facilitated finding unexpected research partners. In fact, in their evaluations, the participants often oriented to tweeting as a tool for community building, which suggests that tweeting might at least partly fall outside the evaluative regime of RA writing. At the same time, tweets were appreciated for promoting published core research genres, and the sharing of sources was seen to support the process of writing in core research genres. In this sense, tweets seem to have a specific place in genre chains related to research publication. While some participants commented on the light-hearted form of the language in tweets, the main value derived from tweets was their mediating/dialogic role to and from other hybrid or core genres (e.g. blogs or RA's).

How do academics value the hybrid online genres in relation to the core research-writing genres in their field?

Academics clearly perceive hybrid online genres as potential part of their research work even if these genres were evaluated as less prestigious than core research genres, such as RA's, monographs, or for the computer/HCI scientists, conference papers. The evaluation in the comparison of the hybrid genres and core genres demonstrates the academics' strong orientation towards institutional merit systems or peer review systems that structure "mechanisms of restriction, authorization, or valorization" (Etrillard, 2019, p. 2) of writing in core research genres. While the hybrid genres were positioned as peripheral to the academics' research work, they can nevertheless add value especially in terms of providing new avenues for literature research and networking. In this way, they are part of academics' professional practices, and can become important for the process of writing for publication (cf. Canagarajah, 2018). As means for promoting core genres, hybrid genres may even form an integral part of a chain of genres related to this kind of writing; for instance, a tweet that promotes a finished research paper increases chances for uptake of the paper. 
Our results demonstrate that the adoption of these genres in an academic's repertoire depends largely on individual preferences. Neither discipline nor career stage seemed to be decisive. In contrast to Weller's (2011) and Barton and McCulloch's findings (2018), early career researchers took up blogging despite its lack of formal institutional recognition.

As part of disciplinary practices, we identified some differences in that historians commented more on the aesthetics of online writing (cf. Hynninen \& Kuteeva, 2017). Some less established research areas in history also seemed to be more receptive than others to use blogs as source of scientific information, and the applied and fast-paced CS/HCI had adopted tweeting on a wider scale than the other fields. There was also more evidence of using online genres for outreach to the wider public by historians and geologists. However, this use depended on their sub-field of research and possible engagement with public institutions such as museums. In these cases, the hybrid genres made sense as part of the disciplinary practices.

Yet contrary to Greenhow and Gleason's (2014: 394) claim, we did not observe an "increasing recognition of different forms of output as legitimate products of research effort". In line with Barton and McCulloch's (2018) findings, distinctions were made between hybrid online and core research genres with the latter counting as "real" research. Clearly, institutional practices affect what is perceived as being of particular value or use (Irvine, 2019). Institutions provide valorisation especially through mechanisms of career progression.

Another connection between the online hybrid genres and core research genres was established via the participants' positioning as active researchers. Those who engaged in these genres evaluated the writing process, the textual product and their own contribution first and foremost in terms of their scholarly work. For instance, blogging made sense if other academics read the texts or if they enlightened the general public with scientific insights. Tweets were central to building and maintaining scholarly networks. At the same time, these genres were seen to allow content and form that was less strictly controlled by peerreviewing processes. Some even mentioned the possibility for being more creative in form and language choice (His08) or language quality (His07). In these cases, the interviewees made a distinction to their core genre writing and positioned themselves as creative writers.

\section{Conclusion}

Our study suggests that scholars' online writing is influenced by the evaluative regimes of research writing (cf. Kuteeva \& Mauranen, 2018), that is, scholars orient to centres of evaluative authority connected to discipline-specific and institutional power structures on international, national and local levels (Nygaard, 2015; Solin \& Hynninen, 2018). Thus, online writing gains its meaning, but not its form, from research writing.

At the same time, the findings demonstrate that online writing contributes to writing in core genres and extends disciplinary practices. The uptake of hybrid genres both in production and consumption broadens the range of genres academics engage in. These genres provide additional tools for networking, which has been identified as a significant factor for research-based writing (Kaufhold \& McGrath, 2019). More specifically, hybrid genres can be part of 
chains of genres and encompass activities that directly contribute to the writing process of core research genres, either in terms of writing alongside a research project (cf. McGrath, 2016) or as a means for early result dissemination.

Hybrid genres are not entirely accepted in academia nor valued by all. This might partly be connected to the relevance of tradition in academia or at least some academic disciplines (e.g. geology) and to the fact that hybrid genres are clearly not central to institutional merit systems. They remain peripheral to academics' practices unless they are combined with other benefits, often related to scholarly and/or writer identity. Considering the comments of our participants on self-actualisation and communicating on one's own terms, these evaluations might relate to traditional ideals of academic freedom which Tusting (2018: 7) identified as being still powerful in the face of encroaching standards of the competitive marketplace. The comments on community participation afforded by tweeting point to traditions of academic collegiality, which is also in tension with increased competitiveness. Thus, how much academics value blogs and tweets depends on how they balance between institutional practices, disciplinary practices, and their identification as scholars (cf. Nygaard, 2017) and as writers. For instance, the balancing act may be a question of weighing personal expectations or experiences of gaining professionally from reading or writing in a particular genre against shared practices in the field (e.g. tweeting in CS/HCI).

Our findings have implications for pedagogic interventions for $\mathrm{PhD}$ students and early career scholars on considering the genres for networking in the field. We have observed an increasing need of online hybrid genres, at least for research projects, which suggests a need for practicing this kind of researchrelated, but more "witty" and light-hearted writing for different audiences and in different languages. What should be noted, however, is that to make this kind of writing sustainable, it has to make sense to the writer. The better the disciplinary and institutional practices are in balance with academics' personal expectations concerning the professional value of online hybrid genres, the likelier it is that academics will write in them.

\section{Acknowledgements}

This work was supported by the Kone Foundation [grant number 088787] and Stockholm University's funds for collaboration with the University of Helsinki [grant number SU FV -5.1.2-2940-17].

\section{Endnote}

1 The Language Regulation in Academia (LaRA) research project, funded by the Kone Foundation, is based at the University of Helsinki and directed by Dr. Anna Solin. The website of the project is at http://www.helsinki.fi/project/lara. 


\section{References}

Barton, D., \& McCulloch, S. (2018). Negotiating tensions around new forms of academic writing. Discourse, Context \& Media, 24, 8-15.

Bazerman, C. (1994). Systems of genres and the enactment of social intentions. In A. Freedman, \& P. Medway (Eds.), Genre and the new rhetoric (pp. 79-101). London: Taylor \& Francis.

Bhatia, V. K. (2004). Worlds of written discourse: A genre-based view, London and New York: Continuum.

Biber, D., \& Finegan, E. (1989). Styles of stance in English: lexical and grammatical marking of evidentiality and affect. Text, 9, 93-124.

Blommaert, J. (2010). The sociolinguistics of globalization. Cambridge: Cambridge University Press.Canagarajah, S. (2018). Materializing 'competence': Perspectives from international STEM scholars. The Modern Language Journal, 102(2), 268-291.

Canagarajah, S. (2018). Materializing 'competence': Perspectives from international STEM scholars. The Modern Language Journal, 102(2), 268-291.

Curry, M. J., \& Lillis, T. (2019). Unpacking the lore on multilingual scholars publishing in English: A discussion paper. Publications, 7(27), 1-14.

Devitt, A. J. (2004). Writing genres. Carbondale: Southern Illinois University Press.

$\mathrm{Du}$ Bois, J. W. (2007). The stance triangle. In R. Englebretson (Ed.) Stancetaking in discourse: Subjectivity, evaluation, interaction (pp. 139-182). Amsterdam: John Benjamins.

Etrillard, A. (2019). Regimes of language, whiteness and social class: The negotiation of sociolinguistic privileges by British migrants in rural France, Language $\mathcal{E}$ Communication, 66, 29-40.

Fairclough, N. (2003). Analysing discourse: Textual analysis for social research. London: Routledge.

Flower, L. (1994). The construction of negotiated meaning: A social cognitive theory of writing. Carbondale, IL: Southern Illinois University Press.

Goodfellow, R., \& Lea, M. (2014). Literacy in the digital university: Critical perspectives on learning, scholarship and technology. London: Routledge.

Greenhow, C., \& Gleason, B. (2014). Social scholarship: reconsidering scholarly practices in the age of social media. British Journal of Educational Technology, 24(3), 392-402.

Hynninen, N. (2018). Impact of digital tools on the research writing process: A case study of collaborative writing in computer science. Discourse, Context $\mathcal{E}$ Media, 24, 16-23.

Hynninen, N., \& Kuteeva, M. (2017). "Good" and "acceptable" English in L2 research writing: Ideals and realities in history and computer science. Journal of English for Academic Purposes, 30, 53-65.

Hynninen, N., \& Kuteeva, M. (2020). Researchers' language practices concerning knowledge production and dissemination: Discourses of mono- and multilingualism. In M. Kuteeva, K. Kaufhold, \& N. Hynninen (Eds.), Language perceptions and practices in multilingual universities (pp. 323-350). Palgrave Macmillan.

Irvine, J. T. (2019). Regimenting ideologies. Language \& Communication, 66, 67-71. https:// doi.org/10.1016/j.langcom.2018.10.005.

Ivanič, R. (1998). Writing and Identity: The Discoursal Construction of Identity in Academic Writing. Amsterdam: John Benjamins.

Jaffe, A. (Ed.) (2009). Stance: Sociolinguistic perspectives. Oxford: Oxford University Press.

Kaufhold, K., \& McGrath, L. (2019). Revisiting the role of 'discipline' in writing for publication in two social sciences. Journal of English for Academic Purposes, 40, 115-128.

Kuteeva, M. (2016). Research blogs, wikis, and tweets. In K. Hyland \& P. Shaw (Eds.), The Routledge handbook of English for academic purposes (pp. 433-445). London: Routledge.

Kuteeva, M., \& Mauranen, A. (2018). Digital academic discourse: Text and contexts: Introduction. Discourse, Context \& Media, 24, 1-7. https://doi.org/10.1016/j.dcm.2018.06.001.

Kvale, S., \& Brinkman, S. (2009). InterViews: Learning the craft of qualitative research interviewing. London: Sage.

Lillis, T. (2013). The sociolinguistics of writing. Edinburgh: Edinburgh University Press. 
Luzón, M. J. (2011). 'Interesting Post, But I Disagree': Social presence and antisocial behaviour in academic weblogs. Applied Linguistics, 32(5), 517-540.

Luzón, M. J. (2018). Features of online ELF in research group blogs written by multilingual scholars. Discourse, Context \& Media, 24, 24-32.

Mason, J. (2002). Qualitative researching. (2nd ed.). London: Sage.

Mauranen, A. (2013). Hybridism, edutainment, and doubt: Science blogging finding its feet. Nordic Journal of English Studies, 13(1), 7-36.

McGrath, L. (2016). Open-access writing: An investigation into the online drafting and revision of a research article in pure mathematics. English for Specific Purposes, 43, 25-36.

Mewburn, I., \& Thomson, P. (2013). Why do academics blog? An analysis of audiences, purposes and challenges. Studies in Higher Education, 38(8), 1105-1119.

Myers, G. (2010). The discourse of blogs and wikis. London: Continuum.

Miller, C. R. (1984). Genre as social action. Quarterly Journal of Speech, 70, 151-167.

Nygaard, L. P. (2017). Publishing and perishing: An academic literacies framework for investigating research productivity. Studies in Higher Education, 42(3), 519-532.

Solin, A., \& Hynninen, N. (2018). Regulating the language of research writing: Disciplinary and institutional mechanisms. Language and Education, 32(6), 494-510.

Street, B. V. (2003). What's "new" in New Literacy Studies? Critical approaches to literacy in theory and practice. Current Issues in Comparative Education, 5(2), 77-91.

Swales, J. M. (2004). Research genres: Exploration and applications. Cambridge: Cambridge University Press.

Thompson, G., \& Hunston, S. (1999). Evaluation: an introduction. In S. Hunston, \& G. Thompson (Eds.), Evaluation in text: Authorial stance and the construction of discourse (pp. 1-27). Oxford: Oxford University Press.

Tusting, K. (2018). The genre regime of research evaluation: Contradictory systems of value around academics' writing. Language and Education, 32(6), 477-493.

Tusting, K., McCulloch, S., Bhatt, I., Hamilton, M., \& Barton, D. (2019). Academics writing: The dynamics of knowledge creation. London: Routledge.

Weller, M., 2011. The digital scholar: How technology is transforming scholarly practice. Basingstoke: Bloomsbury. 


\title{
Appendices
}

\section{Appendix A: Transcription conventions}

\author{
$\underline{\text { Speaker codes }}$ \\ I Interviewer \\ CS\# computer/HCI scientist \\ His\# historian \\ Geo\# geologist
}

$\underline{\text { Transcription symbols }}$

$\begin{array}{ll}. & \text { (micro)pause } \\ . . & \begin{array}{l}\text { suspended or continued statement } \\ \text { end of statement }\end{array} \\ . & \text { laughter } \\ \text { te- } & \text { unfinished word } \\ (\text { text }) & \text { unclear word or utterance } \\ <\text { Text }> & \text { minimal feedback by interviewer } \\ {[\ldots]} & \text { text omitted from transcription } \\ {[\text { text }]} & \text { anonymisation by writers }\end{array}$

\section{Appendix B: Focal excerpt 1, His07}

His07: I have like 500 to 800 words and get something vaguely amusing out there or <Yeah.> or something that is sort of, like all the stuff I wouldn't be able to put in the book $<$ (Right). $>$ basically, where I think, well that's not nearly sufficiently nuanced to actually write down as a scholarly paper $<$ (Okay), okay. $>$ but it's sort of interesting and it's a nice story and, yeah.

I: Yeah, yeah. So would you (call it a), (or), is it (popularised) or is it more towards the scientific side or, how would you (kind of place it)?

His07: I find it hard to describe because it's not, I mean it's not as well thought, as actual scholarly writing in fact I don't really go into anything, in great detail. But it is very, it's very specific. So I don't think you could say like it's (popular), like you wouldn't stumble upon it and think oh everything in this blog is interesting, unless you're me. But I think it sort of touches upon other fields (than what I'm working and) like I know that some of the blogs are interesting to [xx] teachers, for example. And some of them are interesting to historians and.. But, I still don't really know what I want to blog (to). Like at the moment it's really just my personal playground and I sort of think like, (oh) this is amusing I'll write something about it. Sometimes people like it and sometimes they don't and $<$ Okay. Yeah, yeah. Yeah. Yeah. $>$ it doesn't have a massive readership, of of any kind $<$ Yeah, (yeah).> so it doesn't really matter $<$ Yeah. $>$ But, but it is sort of a way, and, when we are talking about language for me as well to sort of, to sort of practice my English, to a degree because it's not (a medium), I'm really fantastically good (at) and I sort of need this, this exercise of playing with words. It would definitely be easier to do it in [L1]. But then you get a very very small segment of people who are able to read it.

I: So, so (tha-), what is the reason that you are writing in English, rather than [L1]?

His07: I, yeah I think both sort of the exercise of of, trying to write in a non-boring way in a language that is not my own. Like it's very easy to be funny in your own language but <Okay.> but doing something sort of slightly witty, is, is very difficult @ @. So I sort of try, try that out there, rather than in my professional writing @ @, which might not be the place to do it. And also because I do sort of share some research interests with colleagues who obviously don't speak [L1]. And increasingly I sort of meet people and know people who don't speak the language and who might be interested in, in these little snippets. So it makes sense I think, to do it. 


\section{Appendix C: Focal excerpt 2, CSO7}

CS07: I use, Twitter as sort of my work thing, so if I see interesting papers or anything like that then I will tweet them, and also most of the people who I follow on Twitter are in, the same field so, if there has been a really interesting paper or something, and they have tweeted about it then I, add it to my, reading list. So.. Yeah, also there's a couple of people's blogs that I follow where, where, where they kinda have sort of maybe like an open discussion about a particular paper or.. or these sorts of things which is, which is.. also really nice. So.. so yeah, Twitter is my sort of, online.. source and sometimes, it.. leads me to things I wouldn't read otherwise, you know, because I wouldn't find them probably if I was searching for but you know, because actually HCI is a really big, field really and so you can't read everything but so.. sometimes if, someone from a slightly different area of HCI will post something and it sounds interesting I'll read that. Yeah, it's.. it's good for that, it's also just good for general, most of the research groups have a Twitter feed and they will update that with whatever they're working on at that time so it also helps you keep track of, what's going on, which is really good as well.

I: $\quad$ Has it changed, (this kind of) use of social media?

CS07: Oh yeah. Yeah, hugely. [...] I'd say, I mean for me even, I don't know how long I've been using Twitter but definitely in the last, I think in the last three years or so I've increased my use more, and started following, more people and taking part in, discussions. I still say our group is not good at.. posting any updates or, where.. Yeah, we need to sort that out.<Okay @@.> Um, because we should really be sharing what we're doing as well but, I, well, CS06 is, CS06 is like, tweets, all the time but.. we, our sort of group one doesn't, really exist. Um.. But yeah, so it has changed a lot and then I, I've ended up getting to, conversations with people who I would never meet otherwise really like, or I would be too scared to go and to talk to them at a conference or whatever, um, and then there's ended up being projects that have started because of, these things. Um.. And yeah, if it wasn't, for the sort of online, things, they would've never happened so, that, that is quite good. Um.. Yeah, I also need to get better, um, regularly.. updating things but, yeah, it's also, it makes it feel more like a bit of a.. or it makes it feel more like you're part of a community 